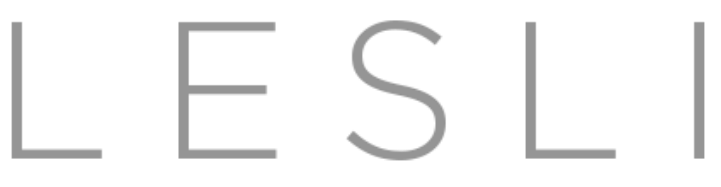

Linguistic Evidence in Security, Law and Intelligence

Volume 1, No. 1 (2013) | ISSN 2327-5596 (online) | DOI 10.5195/lesli.2013.2 | http://lesli-journal.org

\title{
Analysing Deception in Written Witness Statements
}

\author{
Isabel Picornell $\mathrm{PhD}$ \\ Principal, QED Limited, United Kingdom \\ isabel@qed.info
}

\begin{abstract}
Written witness statements are a unique source for the study of high-stakes textual deception. To date, however, there is no distinction in the way that they and other forms of verbal deception have been analysed, with written statements treated as extensions of transcribed versions of oral reports. Given the highly context-dependent nature of cues, it makes sense to take the characteristics of the medium into account when analysing for deceptive language. This study examines the characteristic features of witness narratives and proposes a new approach to search for deception cues. Narratives are treated as a progression of episodes over time, and deception as a progression of acts over time. This allows for the profiling of linguistic bundles in sequence, revealing the statements' internal gradient, and deceivers' choice of deceptive linguistic strategy. Study results suggest that, at least in the context of written witness statements, the weighting of individual features as deception cues is not static but depends on their interaction with other cues, and that detecting deceivers' use of linguistic strategy is an effective vehicle for identifying deception.
\end{abstract}

Keywords: detecting deception; witness statements; narratives; linguistic strategy; text analysis.

\section{Analysing Deception in Written Witness Statements}

To date, the information we have regarding behavioural cues to deception has been largely obtained from laboratory-based experiments dealing with low-consequence lies and psychological perspectives as to how liars should behave when lying. Their success is difficult to quantify as no one has yet identified a single cue, or set of cues, that is consistently identified with deception. DePaulo et al. (2003) suggest that behavioural cues to deception are normally faint unless liars are highly motivated to lie. They are thought to be more motivated to succeed with their deception when the consequences of being caught out are serious; being burdened by guilt at their transgression, or worry about implications to their reputation, or fear of imprisonment should the truth be revealed, results in more obvious behavioural cues which betray deceptive intentions. Such motivation is rarely found in the

\section{$(\mathrm{cc}) \mathrm{Br}_{\mathrm{Br}}$}

Articles in this journal are licensed under a Creative Commons Attribution 3.0 United States License.

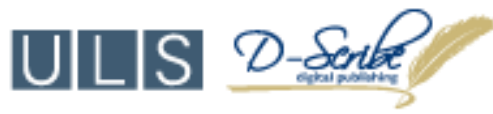

This journal is published by the University Library System, University of Pittsburgh as part of its D-Scribe

Digital Publishing Program and is cosponsored by the University of Pittsburgh Press. 
type of social low-consequence lying common to everyday life; neither can it be simulated under laboratory conditions, given the ethical problems involved. Thus, the study of deception is hampered by the inability to reproduce the conditions under which deception cues may be made more visible.

Deception also suffers with the perception that deception cues should be universal, and that cues such as found in interpersonal oral deception extend into other contexts. In fact, deception cues are highly context-dependent for the simple reason that language and linguistic strategies vary according to context and media. This makes standardised deception detection difficult over a broad range of contexts. Liars may adopt any number of verbal strategies to conceal their lies depending on their circumstances, altering their approach as they think necessary and quickly adapting it in response to feedback. There are basic differences between spoken language (which represent reality as a process) and written language (which represent language as an object), which make it unlikely that deception cues will be consistent across these contexts. Contradictory findings from deception studies in the last three decades indicate that linguistic cues as a deception signal are not even constant within oral or textual contexts.

Only few studies have produced insights into deceptive behaviour during high-stakes lying, and even less into highstakes lying in a textual context. Adams \& Jarvis' (2006) seminal study on deception in written witness statements explored specific linguistic attributes associated with credibility assessment analysis while, more recently, Picornell (2012) compared the effectiveness of linguistic cues (individually and collectively) and linguistic strategies as deception predictors. What emerges from this research is how the unique characteristics of witness statements as textual monologue narratives influence the role of deception cues, reinforcing the finding that deception is a highlytailoured communication construct.

\section{Witness Statements as Textual Narratives}

For the purpose of this study, a written witness statement is defined as a narrative relating to an event witnessed or experienced by the individual writing the statement, and produced as a textual monologue without external intervention or influence ${ }^{1}$. These three aspects - narrative, textual, and monologue - highlight the uniqueness of the medium and the implications for deception analysis.

Witness statements fall within the Labovian definition of narratives of personal experience, being "a report of a sequence of events that have entered into the biography of the [narrator]" (Labov, 1997). The witness is asked (or voluntarily offers) to describe in writing an event of which he or she has first-hand experience. Such statements are rarely straightforward retellings of simple observations; instead, they are the narrators' subjective interpretations of reality. Witness-narrators reinterpret events in the light of their own emotional and social experiences, linguistically reconstructing reality to create meaning as they perceive it to be, manipulating their narratives to get across their own point of view. Out of a multitude of events, narrators select events that they deem to be noteworthy and relevant while omitting others, and then reorder the events to suit their personal theory of causality (Barthes, 1996). This sequentiality, according to narrators' perspective of reality, is the key characteristic of narratives.

\footnotetext{
${ }^{1}$ This definition does to apply to witness statements in the UK, where police officers write the statements in collaboration with witnesses.
} 
Labov's definition of a narrative goes on to include "by a sequence of clauses that correspond to the original events", where the interpretation of the order of events would change if the clauses were reversed (Labov \& Waletsky, 1967). Thus, the chronological ordering of clauses and the semantic function of those clauses are important for providing meaning in narratives. It is the order in which sentences (containing the information) are placed which matters most in creating the plot, not whether the information is true or false (Bruner, 1990). The individuals involved, their mental states, and the events all derive meaning from their place in the overall plot configuration and how they relate to and interact with each other and other features at different levels in the narrative (Barthes, 1996).

In order to be acceptable (and believable) to the reader, each event selected by the narrator needs to be credibly linked together. Indeed, Labov (2001) argues that credibility arises from readers believing that the 'reportable event' (what the narrative is all about) did occur in real time. To achieve this, narrators have to introduce a credible chain of events which explains how the reportable event came about (narrative cohesion) in order to get their theory of causality (coherence) across to their readers. Additional meaning is also conveyed through narrators' selection of lexis and grammar, making word choices which encode their experience of the real world and own internal consciousness, taking into account who else is involved and the circumstances of their participation (Halliday, 1971).

In written witness statements, narrative cohesion, coherence, and lexis and grammar selection come together in a textual monologue context. Research into oral deception indicates that deceivers adopt linguistic strategies according to their degree of preparation (Anolli, Balconi \& Ciceri, 2002; Burgoon, Blair, Qin \& Nunamaker, 2003) and constantly adapt them to the attitude of their addressees (Anolli, Balconi \& Ciceri, 2002). Thus, deceivers are able to choose the most effective approach to persuade or retreat as needed, which enables them to camouflage their deception within the interpersonal environment in which it occurs.

However, communication strategies differ between those engaged in interactive and non-interactive deception (Buller \& Burgoon, 1996). Fundamental differences in deception cues have already been identified between interactive face-to-face conversations and the text-based virtual conversations found in written computer-mediated communication (Woodworth, Hancock \& Goorha, 2005). The gulf is even wider between oral interactive deception and the monologue, narrative context of written witness statements. In such a context, interactive turn-taking is absent and there are no addressees present. Although oral monologues have been included previously in deception studies, these involve speaking to a non-responsive observer according to instructions issued as part of the experiment. Thus, preparing a statement for later consumption by an unknown addressee who is not present at the time of the writing presents a different communication context from speaking to a person who is present, even if that person does not respond. While observers are passive participants in the monologue, they are nevertheless still participants, as distinct from the unknown recipients of written witness statements, who are not there at all.

There are also fundamental differences between spoken and written language which affect lexical and grammatical choices, and therefore deception cues. In speech, language expresses reality as a dynamic process, while writing represents reality as a static object. The transcribed record of the oral account of an event will normally contain shorter clauses, have lower lexical density, and construe properties and processes as verbs and adjectives, compared to a written account of the event which will contain longer clauses, a higher ratio of lexical to grammatical words, and construe the same processes and properties as nouns. 


\section{Narrative Partition}

Current practice in deception analysis of witness statements involves the partitioning of narratives into three sections

-- the reportable event, and what happened before and after. A statement subdivided into three balanced portions is taken to be an indicator of truthfulness, while an imbalance or absence of one or more of the partitions is suggestive of deception (Sapir, 1987; Rudacille, 1994; Rabon, 1996; Adams \& Jarvis, 2006). This practice is said to be based on findings by Johnson, Foley, Suengas, and Raye (1988) that memories of actually experienced events tend to be associated with supporting memories preceding and following the remembered event (Adams \& Jarvis, 2006). However, Johnson et al. were examining differences between individuals recalling memories of actually experienced events and imagined events, which presents a different context to conscious and deliberate fabrication of a story in order to deceive. Furthermore, individuals involved in the experiments used supporting information to justify the true origins of their memories (Johnson et al., 1988). This use of related supporting information is also employed by people to make judgements as to the source of other people's memories, particularly when its veracity is in doubt or the cost of making the wrong decision would be significant (Johnson, Bush \& Mitchell, 1998). Thus, people use the same judgements to evaluate the veracity of other people's memories as they do their own, and are likely to apply that knowledge to make their own false accounts more believable. Indeed, DePaulo et al. (2003) report that deceivers refer to events peripheral to the reportable event more often than truth tellers.

An added difficulty with tripartite division is its subjective nature. The analyst must decide where its boundaries lie. Given the complex nature of serious crime, the line where the central event actually starts and finishes is often blurred, and different analysts may have different opinions where it should be drawn. This partitioning becomes even more problematic if the narrative does not contain a central event, as may happen when a suspect states that he/she was not involved and was somewhere else.

A more effective way of partitioning narratives is to use narrators' own linguistic signposting to manage information flow and facilitate their readers' understanding of events. Found in more 'oral' types of written narratives (including written witness statements), this results in the creation of marked sentence structures which act as segmentation markers and signal the introduction of new discourse packages in the narrative (Prideaux, 1989; Bestgen et al., 2009), alerting readers to major changes in continuity. Deviations from standard sentence construction, such as the placement of subordinate clauses, adverbial clauses and prepositional phrases in sentence initial-position, identify marked structures (Prideaux, 1989; Halliday \& Mathiessen, 2004; Bestgen et al., 2009); these serve to introduce the start of new thematic episode and, therefore, the end of the previous episode. As the decision when to use these structures rests solely with the narratives' authors, there is no ambiguity as to where thematic partitions begin and end.

Thus, a narrative may be described as consisting of a sequence of linking thematic episodes, where meaning is derived from the order of events according to the narrator's personal interpretation of facts and causation.

\section{Narrative Progression and Deception}

The nature of narratives and the sequencing of events have implications for the analysis of deception. A narrative, which consists of sequences of episodes, represents a progression of events over a particular time. As a minimum linguistically, a narrative consists of two independent clauses containing the complication (what happened) separated by a temporal juncture (the time separating from each other the earlier and later actions reported in the clauses. There can be no narrative without the progression of events over time. 
Deception is also a progression. Deception rarely consists of a single behaviour or event; instead, it is a progression of behaviours that happen over time (White \& Burgoon, 2001; Zhou, Burgoon \& Twitchell, 2003). In interactive deception, oral deception cues show substantial variation across time and sequence of the response. Burgoon \& Qin (2006) report that, in an interview context, deceptive profiles in the first half are very different from the second half. Differences in cues are also reported by Zhou, Burgoon \& Twitchell (2003) in text-based email deception, with cues varying over the time of the deception, and no single cue predicting deception at all stages of the exchange.

It should come as no surprise that cues change across the course of a deception. Research in general has tended to examine deception as if it has specific identifiable behavioural characteristics which distinguish it from normal truth-telling. This is a myth. Deception uses the same language as truthful communication; what makes it different is its internal gradient. Internal gradient refers to the series of successive changes to language which arise as a result of individuals manoeuvring their way through language and information selection, given their intentions. Language is influenced by a person's focus, and that in turn is managed by what that person intends to do and how he/she intends to do it (Anolli, Balconi \& Ciceri, 2002). In terms of deception, the finished product (the deception) is a compilation of the deceiver's intentions - to lie or to tell the truth - and the choice of communication strategy which the deceiver adopts to achieve a successful deception.

Identifying language gradient requires a mechanism whereby communication is analysed as a succession of linguistic events. Episode analysis of narratives enables linguistic cues to be treated as fluid and allows for the sequencing of linguistic behaviour to provide insight into how deceivers manage their deception.

\section{Lying and Language}

Lying in written monologue is highly stressful, with none of the advantages of interactive oral and textual deception. Although they have time to plan their narrative, authors of deceptive written witness statements still have to decide how to convey their false account in a way that will appear balanced and consistent with the know truths and, therefore, convincing. Monologue deception lacks the turn-taking which provides periodic feedback with which to check the effectiveness of the strategy; nor do deceivers have the option of silence, having volunteered to produce a statement. Deceivers cannot hide behind the anonymity of the internet and a username, as on online computermediated communication, which might otherwise reduce their apprehension (Valacich, Dennis \& Nunamaker, 1992). There is no single addressee to whom they can direct their communication, and they have no control over the distribution of their statements, which means they have to consider deceiving a larger group of people, further increasing their stress (Zhou \& Zhang, 2006). All this, coupled with the seriousness of the consequences should they be found lying, motivates deceivers to succeed with their lying, leading to high arousal levels which increase the strength of deception cues (DePaulo \& Kirkendol, 1989; DePaulo et al., 2003).

The identification of cues characteristic of deception has long been associated with certain perspectives that deceivers are thought to experience to when they lie -- emotion, cognitive load, and attempted behavioural control (Memon, Vrij \& Bull, 2003), and lack of embracement (Vrij, 2008) -- which underpin physical and linguistic cues to deception. Although these processes are hypothetical and identified retrospectively to explain differences in deceptive behaviour between deceivers and truth tellers (Memon, Vrij \& Bull, 2003), evidence exists that deceivers do experience some of these processes more than truth tellers (Vrij, Semin \& Bull, 1996; Vrij \& Mann, 2001). However, while such behaviour may arise as a result of experiencing those processes, the behaviours are by themselves not indicators of deception; merely that the processes are active in the individual. Fear and anxiety cues are unreliable indicators of deception, as the same process will be experienced by a liar worried about being caught lying and a truth teller worried about not being believed (Othello Error - Ekman, 2001). Neither are cues arising 
from cognitive loading always indicative of deception; some truth tellers experience cognitive loading when telling difficult truths as compared to simple lies (Anolli, Balconi \& Ciceri, 2002).

The difficulty with labelling certain word groups as deception indicators is that it ignores the natural semantic instability of language. Deceivers do not all lie in the same way; the language of deception may be vague, reticent, verbose, negative, subjective, or a combination of two or more. Language is a situational construct, and the author's goals at the time of communication exert a strong influence on construction and word choices (Halliday, 1973). Given the instability of process cues, deception detection may be better served by identifying linguistic strategies commonly used by deceivers.

\section{Linguistic Deception Strategies in Written Narratives}

Several strategic communication patterns have been identified in deceptive interaction in previous studies, characterised by a number of linguistic approaches. These involve the use of ambiguity and vagueness, nonimmediacy and reticence, and disassociation and depersonalisation (Buller \& Burgoon, 1994; Anolli, Balcony \& Ciceri, 2002). Whereas interpersonal deceivers choose their communication strategy according to their interpretation of the preceding utterance or communication, monologue deceivers must decide on their strategy at the outset of their deception. In the absence of interaction feedback in that context, they have little incentive to change their approach. However, there has to be some strategic change to any selected linguistic approach because deceivers cannot provide the same level of information for both the true and false sections of the statement. Even though deceivers may have had opportunity to plan their cover story, the process of translating the false account into words on paper and fitting it in with the known truths requires linguistic adjustments.

The transition is a subtle one, designed to avoid noticeable changes in linguistic direction so as to maintain the perception of continuity. The 'language of deception' is not reserved only for deception but extends into truth telling, so that a seamless linguistic transition is achieved. In effect, deceivers 'slide' in and out of their deceptive accounts, thereby blurring the boundary between truth and lies.

Two main linguistic strategies have been identified in deceptive written witness statements (Picornell, 2012). The first strategy follows a prolix \& personal approach. Here, the deceiver's aim is to be cooperatively vague. The narrative is verbose and highly personal, with over half of clauses containing first person singular pronouns. Contrary to previous studies which find that liars use less first person pronouns than truth tellers, their very high use (50\%+ of clauses) is a key characteristic of the deceptive strategy. However, the pronouns do not all carry the same weight. Alternative self-references to $I$ are manipulated, giving an impression of immediacy associated with truth telling, but which instead allows the author to be removed from the action. High use of $m y$ is a characteristic of this deceptive strategy; the author is still present, but only as the owner of something. In spite of the highly personal nature of the statement, the author remains non-committal. Nearly a third of clauses contain word classes (such as negation, cognition words, verb strings and vague pronoun references) associated with ambiguity or subjective information, the sort of language which pads out a narrative without contributing much that is relevant. The narrator intends to appear helpful by providing a detailed account of the event in which he or she appears to be highly immediate, but renders the information safe through the use of ambiguity and subjective information.

The second strategy is an impersonal one. The approach is direct, with shorter clauses and low ambiguity. Here, the intention is not to hide behind the information but to minimise one's exposure by creating an other focus. There are several variants to this approach, although all are characterised by the use of $3^{\text {rd }}$ person pronouns in at least half the clauses. However, this by itself does not indicate deceit, because truth tellers also make high use of the pronouns when someone else involved in the incident is the centre of their attention, for example when the witness is a simple 
bystander to an event, or is more focused on the wellbeing of the central character, such as a child. This strategy is characterised by the interaction of $3^{\text {rd }}$ person pronouns and self-references, as well as interaction between the various self-references. First person pronoun use may range from low to very high, but what they have in common is deceivers' preference for alternative self-references to $I$. Episode analysis reveals how $I$ use is gradually replaced by $m e$ and/or $m y$ as the deception progresses, while $3^{\text {rd }}$ person pronouns increasingly dominate the statement.

No single deception strategy appears to be associated with any one crime, although completely fictitious accounts appear to favour the prolix \& personal approach. It may be that in the absence of witnesses, deceivers feel freer to construct an entire world of the lie in order to be convincing. This verbose but vague strategy has been identified previously in interpersonal contexts (Anolli, Balconi \& Ciceri, 2002; Buller \& Burgoon, 1994; Dulany, 1982; Hancock, Curry, Goorha \& Woodworth, 2005; Knapp, Hart \& Dennis, 1974; Kuiken 1981), and is specifically associated with addressing silent or acquiescent addressees (Anolli, Balconi \& Ciceri, 2002). The impersonal approach has also been identified in interpersonal communication in previous research (Balconi \& Ciceri, 2002; Buller \& Burgoon, 1994). Also referred to as Depersonalization, Anolli, Ciceri \& Balconi (2002) add the use of the plural we and $u s$ as a feature of this strategy. ${ }^{2}$

This association between certain linguistic strategies and deception in written witness statements may throw light on the contradictory results of previous findings in deception research. Under certain circumstances, it appears that selfreferences are associated with truth telling and $3^{\text {rd }}$ person pronouns are associated with deception; under other circumstances, the reverse is also true. Furthermore, not all self-references are weighted equally, as the strong association between $m y$ and deception suggests. In this context, $m y$ is not an indicator of immediacy but distancing. Similarly, ambiguity features do not always suggest evasion, as they also reflect honest confusion. The point made here is that no single linguistic feature by itself is indicative of truth or deception, because their weighting is flexible, dependent on their association with other cues.

The meaning of pronouns and ambiguity features used in these narratives is strengthened or weakened according to the interaction of these cues with each other. The narrative progression (as measured through its episodes) enables deceivers to adjust the linguistic gradient of statements to suit their deceptive intentions and adapt to the information which they may or may not be able to provide. Results of a double blind study (Picornell, 2012) confirmed that the predictive value of deception cues lies in the way they are used, and not as isolated individual or collective features. When the same cues were used to predict deception in 25 written witness statements, the linguistic strategy approach successfully identified $92 \%$ of statements, while cue counting achieved only an above-chance success.

It must be stressed that what is identified by cue interaction is the use of a linguistic strategy employed for the purpose of deception. It is not suggested that the cues identify the deception itself. Pinocchio's nose remains as elusive as ever.

\footnotetext{
${ }^{2}$ The use of the plural we and us were also noted in the impersonal approach, although plural pronouns were not specifically
} analysed (Picornell, 2012). 


\section{Conclusion}

The findings here support the view of deception as a complex communication construct, and of the highly context dependent nature of deception cues. At least in the context of written witness statements, its monologue narrative nature exerts a material influence on the language of deception. The use of linguistic signposting allows the identification of episode constructions, which highlight breaks in continuity and enable us to follow narrators' changing focus. This provides a vehicle for analysing deception as a progression in a context which relies on the progression of events to create meaning. Deconstructing narratives down into their constituent episodes and linguistically tracking the changing interaction of cues exposes subtle changes in the linguistic gradient of statements, and enables the identification of linguistic strategies associated with deception.

The importance of deception strategy analysis raises questions as to the source of deception cues in witness statements. Do linguistic cues to deception arise from "leakage", or are they the product of a deliberate linguistic strategy to control reader perception? Cues such as negation and cognitive verbs may simply serve to provide difficult-to-verify subjective information with which to pad out a statement, rather than be a product of the

emotional and cognitive burden associated with deception. What makes deceivers choose one deceptive strategy over the other, preferring third party focus to a personal but vague approach? These are issues to be addressed by future research.

\section{References}

Adams, S.H. \& Jarvis, J.P. (2006). Indicators of veracity and deception: an analysis of written statements made to police. International Journal of Speech, Language and the Law, 13 (1), 1-22.

Anolli, L., Balconi, M. \& Ciceri, R. (2003). Linguistic styles in deceptive communication: dubitative ambiguity and elliptic eluding in packaged lies. Social Behavior and Personality, 31, 687-710.

Barthes, R. (1996). An introduction to the structural analysis of narrative. In Onega, S. \& Landa, J.A. (eds) Narratology. New York: Longman.

Bestgen, Y. \& the Psycholinguistics Group of the Spatial Framing Adverbials Project (2009). The discourse function of sentence-initial adverbials: studies in comprehension. Linguistic \& Psycholinguistic Approaches to Text Structuring Conference, 7-14. Paris.

Buller, D.B. \& Burgoon, J.K. (1996). Interpersonal Deception Theory. Communication, 6, 203-242.

Bruner, J. (1990). Acts of Meaning. Cambridge, MA: Harvard University Press.

Buller, D.B. \& Burgoon, J.K. (1994). Deception: strategic and nonstrategic communications. In Daly, J.A. \& Wieman, J.M. (eds), Strategic Interpersonal Communication, 191-223. New Jersey: Erlbaum.

Burgoon, J.K., Blair, J.P., Qin, T. \& Nunamaker Jr, J.F. (2003). Detecting deception through linguistic analysis. Proceedings of the Symposium on Intelligence and Security Informatics. New York: Springer-Verlag.

Burgoon, J.K. \& Qin, T. (2006). The dynamic nature of deceptive verbal communication. Journal of Language and Social Psychology, 25 (1), 76-96.

DePaulo, B.M. \& Kirkendol, S.E. (1989). The Motivational Impairment Effect in the communication of deception. In Yuille, J.C. (ed) Credibility Assessment. Netherlands Kluwer Academic. 
DePaulo, B.M., Lindsay, J.J., Malone, B.E., Muhlenbruck, L. Charlton, K. \& Cooper, H. (2003). Cues to deception. Psychology Bulletin, 129(1), 74-118.

Dulaney Jr, E.F. (1982). Changes in language behavior as a function of veracity. Human Communication Research, 9, 75-82.

Ekman, P. (2001). Telling Lies: Clues to Deceit in the Marketplace, Politics, and Marriage. $3^{\text {rd }}$ edition. London: W.W. Norton \& Company.

Halliday, M.A.K. (1971). Linguistic function and literary style: an inquiry into the language of William Golding's The Inheritors. In Webster, J.J. (ed) Linguistic Studies of Text and Discourse: Volume 2 (Collected Works of M.A.K. Halliday). London: Continuum.

Halliday, M.A.K. (1973). Explorations in the Function of Language (Explorations in Language Study). London: Hodder \& Stoughton.

Halliday, M.A.K. \& Mathiessen, C. (2004). An Introduction to Functional Grammar. 3rd edition. London: Hodder Education.

Hancock, J.T., Curry, L.E., Goorha, S. \& Woodworth, M.T. (2005) .Automated linguistic analysis of deceptive and truthful synchronous computer-mediated communication. HICCS, 1, 22c.

Johnson, M.K., Bush, J.G., \& Mitchell, K.J. (1998). Interpersonal reality monitoring: Judging the sources of other people's memories. Social Cognition, 16, 199-224.

Johnson, M.K., Foley, M.A., Suengas, A.G. \& Raye, C.L. (1988). Phenomenal characteristics of memories for perceived and imagined autobiographical events. Journal of Experimental Psychology: General, 117(4), 371-376.

Knapp, M.L., Hart, R.P. \& Dennis, H.S. (1974). An exploration of deception as a communication construct. Human Communication Research, 1, 15-29.

Kuiken, D. (1981). Nonimmediate language style and inconsistency between private and expressed evaluations. Journal of Experimental Social Psychology, 17, 183-196.

Labov, W. (1997). Some further steps in narrative analysis. The Journal of Narrative and Life History, 7, 395-415.

Labov, W. (2001). Uncovering the Event Structure of Narrative. Georgetown University Round Table.

Georgetown: Georgetown University Press.

Labov, W. \& Waletsky, J. (1967). Narrative analysis. In Helm, J. (ed.) Essays on the Verbal and Visual Arts. Seattle: University of Washington Press.

Memon, A., Vrij, A. \& Bull, R. (2003). Psychology and Law. $2^{\text {nd }}$ edition. Chichester: John Wiley \& Sons.

Prideaux, G.D. (1989). Text data as evidence for language processing principles: the grammar of ordered events.

Language Sciences, 11(1), 27-42.

Rabon, D. (1996). Investigative Discourse Analysis. North Carolina: Carolina Academic Press.

Rudacille, W.C. (1994). Identifying Lies in Disguise. Iowa: Kendall Hunt Publishing Company.

Sapir, A. (1987). Scientific Content Analysis. Phoenix: Laboratory for Scientific Interrogation.

Valacich, J.S., Dennis, A.R. \& Nunamaker, J.F. (1992). Group size and anonymity effects on computer-mediated idea generation. Small Group Research, 2(1), 49-73.

Vrij, A. (2008). Detecting Lies and Deceit: Pitfalls and Opportunities. Chichester: John Wiley \& Sons Ltd. 
Vrij, A., \& Mann, S. (2001). Telling and detecting lies in a high-stake situation: The case of a convicted murderer. Applied Cognitive Psychology, 15, 187-203.

Vrij, A., Semin, G.R. \& Bull, R. (1996). Insight in behavior displayed during deception. Human Communication Research, 22, 544-562.

White, C.H. \& Burgoon, J.K. (2001). Adaptation and communicative design: patterns of interaction in truthful and deceptive conversation. Human Communication Research, 27, 9-37.

Woodworth, M., Hancock, J. \& Goorha, S. (2005). The Motivational Enhancement Effect: implications for our chosen modes of communication in the 21 st century. Proceedings of the 38th Hawaii International Conference on System Sciences.

Zhou, L., Burgoon, J.K. \& Twitchell, D.P. (2003). A longitudinal analysis of language behavior of deception in email. In Chen, H., Moore, R., Zeng, D. \& Leavitt, J. (eds) Intelligence and Security Informatics, 2665, 102-110.

Zhou, L. \& Zhang, D. (2006). A comparison of deceptive behavior in dyad and triadic group decision making in synchronous Computer-mediated communication. Small Group Research, 7(2), 140-164. 